\title{
DRAMA, RITUAL E PERFORMANCE EM VICTOR TURNER
}

Na obra de Victor Turner, o tema do ritual se ergue como um elemento propulsor a ligar e religar suas diferentes fases e interesses multifacetados. ${ }^{\mathrm{I}} \mathrm{O}$ tema irrompe de modo marcante já em Schism and continuity in an African society (Turner, I996) [Cisma e continuidade em uma sociedade africana, doravante SC], seu livro de estreia no cenário antropológico, resultante da tese de doutoramento realizada nos anos 1950 sob a égide do Instituto Rhodes-Livingstone e a orientação de Max Gluckman, a partir de pesquisa junto aos Ndembu. ${ }^{2}$ A aparição do ritual como foco de interesse nesse livro é, de certo modo, inesperada, pois ela ocorre não só na contramão da ênfase mais estritamente sociológica da pesquisa, como a própria notável originalidade e heterodoxia do conceito de drama social ali forjado tende a sombreá-la. ${ }^{3}$

Está certo que ritual já era assunto central na discussão dos sistemas políticos africanos (Fortes \& Evans-Pritchard, I950), e também para Max Gluckman (1963; 1974) entre tantos outros. ${ }^{4}$ Mas Turner estava especificamente interessado na simbolização ritual, assim como Audrey Richards (I982) e Monica Wilson (I954; I957). Em muitos trechos de Schism and continuity, Turner reiterou a promessa de um livro vindouro integralmente dedicado ao que ele chamava então de "estrutura cultural do ritual Ndembu" (Turner, I996: 303). Esse impulso, de certo modo ali reprimido, geraria efetivamente o conjunto de artigos e ensaios que, escritos entre I957-I958 e I964, logo seriam reunidos em Floresta de símbolos (2005), Drums of affliction (1968) e Revelation and divina- 
tion (1975a).5 Em Schism and continuity, entretanto, um ritual e um símbolo ritual já detêm a atenção do autor: Chihamba e Kavula.

Chihamba é um dos mais importantes rituais de cura Ndembu presenciados e analisados por Victor Turner, sempre em companhia de sua esposa Edith. ${ }^{6}$ Kavula, por sua vez, é um personagem liminar que surge, seja como ser imaginado em narrativas exegéticas, seja como artefato manipulado no ritual. Chihamba parece ter se imposto por si mesmo ao autor e com ele se rompem - ou se suspendem por um momento - os próprios pruridos de Turner em empreender uma análise "cultural" [sic] do ritual. O breve exame do simbolismo do Chihamba (Turner, 1996: 303-307) fulgura, assim, como um momento ele mesmo intersticial em Schism and continuity. Pois, mesmo "tentando isolar tanto quanto possível as relações e os processos sociais de seu invólucro cultural", e renovando a promessa de um futuro livro devotado a esse assunto específico, Turner concede a si mesmo, nesse pequeno trecho, permissão para fazer um pouco dessa análise. Afinal "algum tipo de relato das principais caraterísticas culturais do ritual Chihamba é necessário, se queremos apreender claramente as suas implicações sociológicas" (Turner, I996: 303). Naquele momento, talvez nem ele mesmo se desse conta da força criativa dessa liminaridade mútua, e de que o tal "invólucro cultural" que ali reluzia por meio dos símbolos rituais logo se tornaria o coração de sua matéria antropológica. ${ }^{8}$

Kavula e Chihamba reaparecerão mais tarde, com particular intensidade, em Revelation and divination [RD] (Turner, 1975a). Embora o artigo "Chihamba the white spirit: A ritual drama of the Ndembu", que compõe o primeiro capítulo, tenha sido originalmente publicado em I962, esse livro, como bem indica sua densa introdução, marca um novo momento na trajetória intelectual de Turner. Nele, o ritual Chihamba e o personagem Kavula funcionam a um só tempo como redenção e revelação, e permitem, a nós leitores, observar com nitidez a distância que separa o pesquisador aprendiz do antropólogo maduro e transformado pela própria experiência de vida junto aos Ndembus. No início de suas pesquisas, Turner (1953: 336) acreditou que abordaria as danças e os rituais de um povo iletrado e analfabeto situado "na retaguarda da história" que criara, entretanto, "uma estrutura religiosa harmoniosa e consistente". Em RD, o autor nos confessa o quanto suas pesquisas o haviam transformado: "Decifrar as formas rituais e descobrir o que gera as ações simbólicas pode ser mais próximo de nosso crescimento cultural do que nós supusemos" (Turner, I975a: 31).

Nesse ínterim, entre meados dos anos I950 e o final dos anos 1960,9 realizaram-se as ricas análises simbólicas empreendidas a partir da etnografia dos rituais que consagraram Turner na disciplina (Lenclud, I992). Especialmente em Floresta dos símbolos [FS] (Turner, 2005), publicado originalmente em I967, encontramos os dois seminais artigos que concentram as formulações e fecun- 
dos insights teóricos acerca das simbolizações rituais: "Símbolos no ritual Ndembu" (1965) e "Betwix, between: o período liminar nos ritos de passagem" (I964). Mas há também O processo ritual [PR] (I974), publicado originalmente em I969, que elabora a ousada transição do conceito de liminaridade àquele de communitas. ${ }^{\text {Io }}$ Liminaridade, como a entendeu Van Gennep (1977), é uma fase peculiar na sequência padronizada dos rituais de passagem. Seus atributos simbólicos característicos, entretanto, levariam Turner à formulação do conceito de communitas, e a liminaridade tornar-se-ia uma das possíveis manifestações da communitas: uma forma de relacionamento humano primordial sempre contraposta à forma estruturada e hierarquizada do relacionamento social feito de posições bem demarcadas. Ora, essa metamorfose conceitual exprimia também a decidida incorporação do mundo ocidental e de uma ampla perspectiva comparativa nas preocupações do autor; e o material etnográfico Ndembu passaria, doravante, a dialogar com aquilo que Turner denominaria um pouco depois de "gêneros simbólicos em sociedades de larga escala" (Turner, I982: 24): movimentos milenaristas, os hippies, os fracos e marginalizados, as ordens medicantes. Essa amplitude comparativa prossegue com Dramas, campos e metáforas (2008), publicado originalmente em I974, que estende, por sua vez, o conceito de drama social para materiais históricos e contemporâneos ocidentais, examinando processos revolucionários, crises políticas e peregrinações cristãs.

Vistos retrospectivamente, o ritual Chihamba e o personagem mítico Kavula fazem, assim, irromper, no livro de estreia de Victor Turner, seu profundo interesse pelos símbolos e por sua ação na experiência social. Em RD (Turner, I975a), Chihamba e Kavula funcionam também como operadores de uma despedida e como prenúncio de uma nova passagem. Depois desse livro, aprofundam-se as incursões cada vez mais decididas do autor para além das fronteiras disciplinares, em especial na área da experimentação teatral, que conduziriam a From ritual to theatre. The human seriousness of play (Turner, I982), seu último livro autoral publicado em vida.

Com suas aparições intensas e pontuais, Chihamba e Kavula parecem condensar feixes de interesses teóricos que se ramificam pelos meandros da obra de Victor Turner. Buscando seu inquieto movimento, talvez possamos também nos movimentar, com alguma liberdade, por entre as noções de drama social, de símbolo ritual e de performance, três fulcros das contribuições centrais de Victor Turner à teoria antropológica. 


\section{SOBRE O ESTILO DE VICTOR TURNER}

Não se trata, então, de buscar nessa obra uma sistematicidade que insiste em se desmanchar, malgrado as remissões e repetições compulsivas do autor a seus próprios livros e ideias que acompanham a expansão de seus interesses. ${ }^{\text {II }}$ Muito menos de buscar definições. Com relação a esses dois aspectos - sistematicidade teórica e definições boas para usar e fazer pensar - Victor Turner oscila: o brilho de seus insights e ideias convive, por vezes, com um grande ecletismo e mesmo inconsistências. Quando não apreendido de modo mais orgânico e dinâmico, nosso autor pode nos confundir e mesmo induzir à rigidez ou a equívocos. Um bom exemplo disso é a surpreendente pobreza, bem indicada por Grimes (I990: I4I), da definição de ritual que, nunca revista por Turner, abre o já mencionado artigo "Símbolos no ritual Ndembu": "Por 'ritual', entendo o comportamento formal prescrito para ocasiões não devotadas à rotina tecnológica, tendo como referência a crença em seres ou poderes místicos" (Turner, 2005: 49). ${ }^{\text {I2 }}$ O próprio Turner estava longe de operar dentro dos estreitos e problemáticos limites teóricos dessa definição. O conceito de símbolo ritual foi talvez o mais densamente elaborado pelo autor (Cavalcanti, 20I2), justamente nesse artigo. Esse conceito - centrado na ideia dos símbolos como propulsores da ação social e pessoal na arena pública, e baseado nas propriedades simbólicas de multivocalidade, complexidade associativa e abertura para diversos campos semânticos, ambiguidade, polaridade sensorial e ideológica ${ }^{13}$ - está na base da proposta turneriana de uma simbologia processual e comparativa (Turner, I975b: I55): uma abordagem focada nos "símbolos individuais, em seus campos semânticos e destino processual na medida em que se movimentam através do cenário de uma performance ritual específica e reaparecem em outros tipos de ritual, ou mesmo se transferem de um gênero para o outro, por exemplo, do ritual para um ciclo mítico, para um épico, para um conto [....]" (Turner, I982: 22, ênfase do autor). Entretanto, malgrado esses esforços de sistematização, as teorias turnerianas do ritual permanecem, como também já indicou Grimes (I990), assistemáticas. ${ }^{14}$

O inegável interesse dessa obra parece situar-se, assim, não apenas em seus fulcros conceituais, mas, especialmente, em seu "sense of ritual" (Grimes, I990), ou seja, em sua apreensão teórico-existencial do ritual. Com seu interesse pelos rituais e pelas simbolizações, Victor Turner nos trouxe uma incomparável apreensão do sentido do vivido na experiência social.

Como já assinalou DaMatta (2005: 25), entre os anos I950-I960 Mary Douglas (1976), Edmund Leach (DaMatta, I983) e Victor Turner renovaram os estudos dos rituais ao tomar como foco a ambiguidade, os estados intermediários, as contradições, o paradoxo em uma antropologia até então preocupada com a padronização. Entre eles, contudo, Victor Turner seria aquele que 
manteve o foco de interesse permanente e intenso nos símbolos em movimento e nos sistemas de ação. Turner navegou decididamente na torrente durkheimiana oriunda da visão do ritual como a própria sociedade em ato (Turner, 2005: 69; 1987: 77), como o lugar por excelência de um tipo de experiência na qual o poder transformador e criativo das representações coletivas se realiza na consciência dos sujeitos (Durkheim, I996).

No cenário da antropologia da segunda metade do século XX, Victor Turner pode ser contraposto de forma interessante a Claude Lévi-Strauss. Não só por reproduzirem, de certo modo, e cada um à sua própria maneira, a longa disputa da primazia conceitual entre mito e rito na literatura antropológica, mas também pelo contraste nos estilos. Lévi-Strauss é o arquiteto de sinfonias teóricas cujos temas anunciados sempre respondem uns aos outros, perseguindo-se e desdobrando-se metodicamente. Turner, pelo contrário, embrenhou-se, e muitas vezes perdeu-se, por entre as colunas vivas de suas florestas de símbolos. Porém não é gratuito que justamente no "Finale" de o homem nu, o quarto volume de suas Mitológicas, Lévi-Strauss devote uma longa reflexão a responder às críticas de que ele desconsideraria, em sua obra, a importância da vida afetiva (Lévi-Strauss, 20II: 643-670). Ora, essas críticas provêm da antropologia social britânica, com os autores que justamente tomaram o ritual e a ação simbólica como foco de interesse (entre eles Meyer Fortes, Edmund Leach e Thomas Beidelman), e Lévi-Strauss parece deter-se especialmente em Victor Turner (1968; I974; 2005) cuja antropologia, efetivamente, transforma a ideia de uma "sujeição ao vivido" (Lévi-Strauss, I976) em um comprazer-se com o vivido. Ritual, em Victor Turner, conduz a uma espécie de redenção pela imersão na experiência vital compartilhada, onde o tempo vira fluxo, finitude, aflições, sofrimento, cura, contradições, e sempre empatia e afeições. Turner nos interpela desde esse lugar, nos convidando a compartilhar de sua própria experiência da communitas, a forma primordial, nos diria ele mais tarde, do relacionamento humano (I975a). Em sua dimensão de performance autoral, os textos de Victor Turner são sempre, eles mesmos, gestos dramáticos.

\section{DRAMA SOCIAL}

Como sabemos, o conceito de drama social foi formulado por Victor Turner em Schism and continuity (I996: 9I-94). A noção tem muitos aspectos e sua face mais evidente, e talvez mais difundida, é a sociológica que percebe e integra o conflito como um mecanismo produtor da dinâmica e da unidade da vida social. Max Gluckman (I990) saudou a inovação trazida pelo conceito, que permitia a análise processual da vida social. A noção fornecia ao etnógrafo, efetivamente, uma moldura a um só tempo analítica e descritiva de seu material. 
No plano descritivo, por conflito compreendiam-se as brigas e querelas que, de tempos em tempos, eclodiam das mais diversas maneiras no dia a dia da vida aldeã dos Ndembu. Geradas pelo rompimento de alguma conduta esperada entre os atores sociais, essas brigas se desdobravam, como descobriu Turner, em um processo que obedecia sempre a uma sequência padronizada de ações englobadas pelas quatro conhecidas fases do drama social: I. crise: tudo começa com o reconhecimento de uma crise que irrompe no cotidiano tornando manifestas tensões latentes inerentes às relações e interações sociais.

2. ampliação da crise: os sujeitos/atores atingidos atuam e acionam suas redes de parentela, relações de vizinhança e amizade; a crise se amplia gradualmente, atingindo novas esferas e envolvendo cada vez mais atores.

3. regeneração: alguns dos sujeitos/atores envolvidos mobilizam-se em prol de soluções e esforços de conciliação que implicam sempre a realização de ações rituais e amplos rituais coletivos.

4. rearranjo ou cisão: se bem-sucedidos, os esforços da fase anterior implicam um rearranjo e redefinições de posições e relações e, se malsucedidos, configuram o rompimento do grupo aldeão, traduzido na sua cisão que segue as clivagens de parentesco e na criação de uma nova aldeia organizada, contudo, segundo os mesmos princípios estruturais.

Esse modelo descritivo é também analítico e agrega tanto dimensões mais estritamente sociológicas como acopla, de modo criativo, as determinações socioestruturais das condutas sociais a margens de escolhas e atuação subjetivas e individualizadas. Os atores sociais dos dramas analisados por Victor Turner logo se tornam personagens vívidos, cheios de traços peculiares e características, qualidades e defeitos, muito pessoais. ${ }^{15}$ Mais do que isso, a experiência vivida por eles no desenrolar do drama é subjetivada, produz reflexividade, e pode modificar o próprio sujeito e seu grupo. Todas essas características seriam mais tarde transpostas por Turner para a ideia de performance (Turner, I987b). ${ }^{16}$

No plano sociológico, o conceito de drama social considera como conflito a tensão latente produzida na vida social pela atuação constante de princípios estruturais contraditórios. Esses princípios, que não são apreendidos diretamente pela consciência dos atores, pressionam, entretanto, sua conduta em direções divergentes. É justamente a ideia de latência de conflitos, e de sua dimensão por vezes inconsciente, que instaura o lugar crítico da simbolização ritual na obra subsequente de Turner. Porém, por ora, é preciso chegar perto dos dados etnográficos para compreender os dramas vividos pelos Ndembu e o papel que Turner atribuirá ao ritual nesse processo. 


\section{ALGUMA ETNOGRAFIA}

A base político-residencial das aldeias Ndembu organizava-se pelo princípio da matrilinearidade que norteava o ideal de continuidade e permanência da vida aldeã através da sucessão de diferentes gerações de chefes. Essa almejada continuidade, entretanto, não era objetivo facilmente alcançado na experiência social concreta. Nos anos I950, o padrão temporal médio de duração de uma aldeia seria de seis gerações e, de um total de 64 aldeias levantadas na mostra quantitativa empreendida por Turner, apenas uma aldeia perdurava há doze gerações. A aldeia Mukanza, base do estudo de caso realizado, existia então há nove gerações (Turner, I996: 83). ${ }^{\mathrm{I}}$

As razões dessa dificuldade são atribuídas por Turner à associação contraditória existente na organização social Ndembu entre o princípio da matrilinearidade (a definição da ascendência por linha materna, via irmão da mãe) e a regra de casamento virilocal (as mulheres, ao se casarem, deslocavam-se para a aldeia dos maridos). A vigência das duas regras impunha a um grupo de irmãos uterinos a separação residencial dos parentes com os quais convivera na infância. Via de regra, esse hipotético grupo de irmãos, em função do casamento virilocal de sua mãe, terá crescido na aldeia de seu pai, ou seja, no seio da matrilinhagem que comanda a rede de parentesco de seu pai. Ao se casarem, os homens desse grupo de irmãos tenderão a levar as esposas para outra aldeia, aquela de sua própria matrilinhagem. Essa mudança residencial no ingresso da idade adulta fazia com que o grupo de irmãos tendesse a entrar em conflito de lealdade com a nova aldeia como um todo, constituindo uma primeira provável "unidade de fissão" a ameaçar a unidade aldeã (Turner, I996: cap. VII). Por sua vez, as irmãs desse mesmo grupo hipotético - que, quando casam, deslocam-se para a aldeia do marido - manteriam, mesmo depois de casadas, um forte laço com seus irmãos. Com seus filhos, elas formam uma base potencial importante para os grupos de apoio político a um homem/irmão sênior e aspirante à liderança aldeã. É interessante observar desde já que, embora essa tensão perpassasse todas as esferas da vida Ndembu, é o primeiro casamento de uma jovem que revela "abertamente a incompatibilidade existente entre a matrilinearidade e a virilocalidade" e o ritual Nkang'a (rito de puberdade feminino) seria aquele que enfrentaria de modo mais explícito essas tendências conflitantes inerentes à estrutura social Ndembu (Turner, 2005: 20I).

Em Schism and continuity, com o estudo dos episódios alinhados nos primeiros cinco dramas sociais analisados, Turner desvendou a forte tensão existente entre as duas principais linhagens - Nyachitang'a e Malabu - cuja aliança selava a unidade da aldeia Mukanza. Essa aliança consolidara-se no casamento do chefe da aldeia Mukanza Kabinda (sênior da linhagem Nyachitang'a) com Nyamukola (sênior da linhagem Malabu). Sandombu é um 
dos membros seniores da mesma linhagem Nyachitang'a do chefe da aldeia, que tinha como segunda esposa justamente a filha do casal Mukanza e Nyamukola. Sandombu é o personagem que abre o primeiro drama narrado por Turner - "Um dia, em I947, Sandombu caçou um antílope..." - e quem introduz o conflito que movimenta o enredo dos dramas: a aspiração dos homens seniores à chefia da aldeia (Turner, 1996: 95).

No drama V, o último dos dramas sociais analisados no capítulo V, intitulado "Sandombu injuria e é injuriado (minhas próprias observações)" (Turner, I996: I57-I68), a sequência de ações se inicia com o conflito de Sandombu com sua segunda esposa. No calor dos desentendimentos, Sandombu teria acusado sua sogra, Nyamukola (da linhagem Malabu) de ter passado um feitiço a sua filha para que esta, por sua vez, o enfeitiçasse. Enquanto tudo isso acontecia, entretanto, num episódio de conflito entre a aldeia Mukanza e uma aldeia vizinha, o mesmo Sandombu, que já penara como ator dos diversos conflitos narrados nos outros dramas, defendeu ágil e publicamente a sua própria aldeia. Outro adulto da aldeia Mukanza, membro da linhagem Malabu (a mesma de Nyamukola) defendeu, então, Sandombu, que se retratou publicamente e pagou à sua sogra apenas uma multa. A crise exposta desembocará, assim, não no aprofundamento da tensão e na eventual fratura da unidade da aldeia, mas em realinhamentos. Ora, a regeneração final é promovida justamente pela realização do ritual Chihamba, examinado no capítulo X, intitulado "A função politicamente integrativa do ritual" (Turner, I996: $288-317) .{ }^{18}$

\section{DO DRAMA SOCIAL AO RITUAL}

Ao formular o conceito de drama social, Victor Turner fez a contradição entre o princípio da matrilinearidade e a regra de virilocalidade funcionar como o motor de um destino visto como inevitavelmente trágico da vida aldeã Ndembu. O autor criou, como observei em outra ocasião (Cavalcanti, 2007), um suspense na narrativa etnográfica que faz com que, a cada conflito presenciado ou relatado, a sombra da cisão ameace a aliança sobre a qual repousa a unidade da aldeia Mukanza: "A situação em uma aldeia Ndembu é muito próxima àquela do drama grego em que testemunhamos o desamparo do ser humano perante o destino: nesse caso, entretanto, o destino são as necessidades do processo social" (Turner, I996: 94). A ideia orgânica e propriamente dramatúrgica do drama social (Geertz, 2007; Langer, I953) no qual uma fase gesta a outra desde dentro, as ações respondendo-se umas às outras e desdobrando-se em novas ações, trouxe certamente a temporalidade processual como uma dimensão central para a apreensão do dinamismo da vida social. Porém, é preciso notar que, sempre situado em um processo social mais am- 
plo, o conceito de drama social opera a partir da construção de uma moldura temporal especial e de ordem narrativa, não se trata apenas de sequências particulares de ações e reações encadeadas: o ritmo dos acontecimentos é dado por sua forma narrativa e está sempre sobredeterminado pelo destino final antecipado, não importando quão cedo ou tarde ele se realizará, ou mesmo se ele, afinal, se realizará ou não. ${ }^{\text {I9 }}$

Dentro dessa sequência de episódios e atores submetidos à dinâmica de um conflito socioestrutural, a realização de um ritual abre uma espécie de brecha, não só na vida social Ndembu, como na própria reflexão do autor. Por essa brecha insinua-se uma outra dimensão da temporalidade por onde o símbolo ritual escapa e atua. Na liminaridade ritual, através da simbolização, o tempo ganha a intensidade e a qualidade transformadora e reflexiva, produzindo a experiência pelos sujeitos da fusão entre ação e consciência (Turner, I982; 1987b) que será também mais tarde um dos elementos na conceituação turneriana da performance.

Em seu primeiro trabalho sobre os Lunda-Ndembus (Turner, I953), o interesse de Turner pelos rituais já é explícito, e ele nos apresenta uma útil descrição das diferentes modalidades rituais encontradas. ${ }^{20}$ Haveria os inúmeros rituais de aflição, relacionados à associação do infortúnio e da doença com a ação de espíritos dos mortos. (Mais tarde, em The drums of affliction [1968: 52] Turner nos dirá mesmo que, entre os Ndembu, os rituais de aflição eram a forma característica do culto dos ancestrais.) Dentre as principais formas da aflição, já se destaca Chihamba, termo usado também para denominar o próprio ritual, que abarca tanto homens como mulheres e trata de desordens reprodutivas ou da doença de modo geral. Haveria também os ritos de crise de vida: ${ }^{21}$ Mukanda, a iniciação masculina; Nkang'a, a iniciação feminina; e os funerais. ${ }^{22}$

Assim como ocorreu com as acusações de feitiçaria entre os Azande (Evans-Pritchard, 2005), a atividade ritual pontuava a vida cotidiana dos Ndembu e era um assunto recorrente entre os aldeãos. Turner logo se daria conta de que era preciso descobrir "o modo como os ndembos [sic] sentem seu próprio ritual e o que pensam a respeito dele" (Turner, 1974: 25) e seria levado à convicção de que, no estudo dos ritos, estava "a chave para compreender-se a constituição essencial das sociedades humanas" (Wilson, I954 apud Turner, I974: 19).

Em Schism and continuity, Turner nos conta ter assistido a 3I performances de I5 tipos de ritos de aflição, ritos que visam transformar uma perturbação em poder curativo: “o adepto aplaca o espírito ofendido" em um processo que trata de "trazer o ancestral ofendido de volta à memória" (Turner, 1996: 298); e detalhará, no capítulo X, o ritual Chihamba assistido em seu segundo período de permanência. ${ }^{23}$ Chihamba era considerado "um ritual muito pesado"; "um espírito que se manifesta no Chihamba pode matar a 
pessoa afligida"; "uma manifestação específica do espírito ancestral" (Turner, I996: 303); "uma espécie de compêndio de todos os infortúnios que podem acontecer a alguém" (Turner, I996: 304). Turner indica que os 71 adeptos/ candidatos participantes eram de 20 aldeias diferentes, pertencentes, por sua vez, a sete regiões diferentes. Registra também o grande número de espectadores nas fases públicas do ritual, que teria chegado a 400 pessoas em uma das noites (Turner, I996: 312-313). A principal paciente/iniciante no ritual relatado era Nyamukola, a esposa do chefe Mukanza Kabinda que havia sido foco das tensões indicadas no drama V, mencionado acima. E o principal patrono do ritual era justamente Sandombu, o genro que a acusara de desejar enfeitiçá-lo por meio de sua filha (Turner, I996: 309).

Nesse culto emerge o personagem/artefato Kavula, que não é, entretanto, o espírito ancestral (a ser nomeado e rememorado) que aflige o paciente/candidato a adepto, mas um espírito que tem existência independente (Turner, I996: 304). Na noite do primeiro dia da terceira fase do Chihamba, Kavula (um adepto sênior disfarçado) atua como um palhaço. Com voz gutural, ele escarnece e fala indecências para os candidatos/pacientes na casa do principal paciente/parente do culto em questão, no caso, a casa de Nyamukola e do chefe da aldeia. Nessa ocasião, Kavula faz estranhas perguntas a todos os candidatos/pacientes e atribui a cada um nomes rituais característicos e exclusivos (Turner, I996: 304). No dia seguinte, se faz uma armação móvel em um lugar secreto na mata próxima da aldeia. Essa armação, uma espécie de boneco, será agora Kavula. ${ }^{24}$ Uma corda é amarrada a esse artefato e um adepto sênior o manipula, fazendo-o dançar. Tratados como "escravos de Kavula", vestindo-se de andrajos, todos se ajoelham e rastejam diante da imagem branca de Kavula (isto é, tornada branca, por um lençol ou uma pele animal embranquecida pela mandioca). Kavula é, nesse momento, "aquele que tudo sabe e que devemos louvar": "Um por um eles rastejam em direção à cobertura de folhas que circunda a imagem branca de Kavula, batendo a cabeça no chão conforme avançam, primeiro para um lado e depois para o outro. As mulheres espremem seus seios para aleitar o chefe enquanto avançam. Kavula, nesse momento, é comparado a Mwantiyanvwa [o ancestral originário]" (Turner, I996: 304). Ao alcançar o ancestral/artefato, cada paciente/candidato é, então, instruído a matar Kavula, batendo em sua cabeça com um chocalho (um chocalho de forma especial e especialmente esculpido para o adepto/paciente). Os candidatos são, em seguida, levados embora pelos adeptos seniores. Quando voltam, não mais encontram o lençol branco, e o pequeno altar está cheio do sangue de uma galinha sacrificada. Os adeptos seniores dizem aos candidatos que eles mataram Kavula. A capacidade de cura é adquirida depois de "matar" Kavula. 


\section{o SíMBOLO EM AÇÃo}

O estudo desse ritual legitima-se, em um primeira instância, pelo viés sociológico. A vida social Ndembu, cheia de clivagens e conflitos, seria extremamente instável, divórcios seriam frequentes, e Turner menciona diversas vezes o acentuado individualismo dos Ndembu, homens e mulheres em seu ir e vir constante por entre diferentes aldeias e grupos de parentesco. Turner dialoga e contrapõe-se, todo o tempo, a Meyer Fortes e Evans-Pritchard, ${ }^{25}$ pois entre os Ndembu, nos diz o autor, as instâncias políticas seriam pouco operantes para garantir sua unidade.

Do ponto de vista de sua organização social, como a afiliação às associações de culto é individualizada, como essas associações são elas mesmas transitórias, e como em cada uma delas há indivíduos das mais diversas aldeias e de diferentes matrilinhagens, a realização de um ritual, por si só, reforçaria os laços de pertencimento mútuo dos Ndembu. O argumento sociológico é fecundo, pois são justamente as relações multifacetadas entre grupos e pessoas que favorecem o sentido de pertencimento a um mesmo povo, um subgrupo dentro da grande nação Lunda. A unidade de pertencimento é alcançada não apesar do conflito, mas através do conflito: "Assim a fissão e a mobilidade, ao mesmo tempo em que desfazem aldeias, entrelaçam a nação, que não dispõe de nenhuma autoridade política efetiva e geral" (Turner, I996: 289).

Esse entrelaçamento, no entanto, não se dá automaticamente no plano das relações sociais tout court, é um efeito produzido pelos símbolos rituais, que não enfatizariam esta ou aquela matrilinhagem, nem a ocupação comum de localidades particulares. Enfatizariam sempre, nos diz Turner, os interesses que todos os Ndembus teriam em comum para além de suas muitas clivagens: nos rituais, "a aflição de cada um é preocupação de todos" (Turner, I996: 302). Os infortúnios comuns da humanidade tornam-se ocasiões para a reafirmação dos valores comuns aos Ndembus como um todo" (Turner, I996: 30I). A unidade dos Ndembu não seria assim política, mas moral (Turner, I996: 289-290): trata-se, em suma, de uma "comunidade de sofrimento", como as sinalaria, no prefácio de I957, Max Gluckman (Turner, I996: XIX).

Ao longo desse capítulo X, Turner oscila bastante, qualificando o ritual inúmeras vezes como um mecanismo de compensação diante de tamanha fraqueza e fragmentação política. A própria profusão de tipos e a frequência de performances rituais (Turner utiliza aqui a noção de modo descritivo) são vistas muitas vezes como "confissões de fracasso no poder dos mecanismos seculares em regenerar e absorver os conflitos que emergem dentro e entre os grupos locais e de parentesco" (Turner, I996: 289). ${ }^{26}$ Suas reflexões, entretanto, deslocam também radicalmente a compreensão da natureza do vínculo social, que passa a depender da produção simbólica. 
$\mathrm{Na}$ interpretação do ritual em geral, elaborada a partir da experiência dos rituais Ndembu, emerge, entretanto, um forte bias cultural, bem indicado por DaMatta (2000), pois o ritual em Victor Turner, ao tornar manifestos, por meio simbólico, conflitos latentes, parece sempre trabalhar em prol da construção da unidade do grupo. ${ }^{27}$

Mas há também aqui um poderoso amálgama de ideias que não cessaram de se desdobrar. Entre elas está o início do gradual deslocamento da visão do ritual como integrando uma fase específica de um processo social à consideração do ritual em si como um processo (Turner, 2005: 49; I974). A multiplicidade de rituais encontrada entre os Ndembu, por sua vez, conduz à fecunda ideia de que "Em cada tipo de ritual Ndembu, um grupo ou categoria diferente transforma-se no elemento social em foco" (Turner, 2005: 53). Diferentes aspectos e valores da vida social são assim perspectivados através de diferentes processos rituais (DaMatta, I979).

Em Chihamba há, especialmente, Kavula, a um só tempo símbolo ritual em ação, liminaridade e performance, dependendo de como quisermos vê-lo. Na exegese nativa, nos diz Turner, Kavula seria um estranho ser sobrenatural, nomeado por um termo arcaico para designar o relâmpago, ligado também ao termo existente para a chuva, a mandioca e outros grãos cultivados. Na sequência do Chihamba, Kavula opera como um ser liminar, que articula os temas da destruição e da morte àqueles da renovação e da cura, e nos contextos narrativo e ritual transita entre um e outro domínios semânticos. Kavula é um símbolo ambivalente, nos diz Turner, que preside sobre a fertilidade, simboliza a um só tempo tanto a autoridade benevolente (o avô que faz brincadeiras jocosas com os netos, e pode retirar a doença e o infortúnio), como o lado mais opressivo da autoridade ancestral em uma sociedade cheia de conflitos de parentesco e com senhores e escravos (Turner, I996: 305). Kavula reúne os conhecidos atributos do símbolo ritual formulados por Victor Turner (2005). Torna manifesto um conflito latente através do jogo esquecimento/memória da ancestral ofendida; agrega os polos sensorial e ideológico dos símbolos dominantes; condensa valores e imagens, desloca afeições, expressa e resolve a ambivalência. Apenas depois de matar Kavula o adepto/paciente está habilitado para a cura: o símbolo vincula ao grupo e elabora a ligação do sujeito com a sua própria experiência, e por isso ele pode transformar.

Ao mesmo tempo, Kavula é performance num sentido mais próximo à teatralização, é disfarce e manipulação de artefato, produção de cenas e condutas que, mesmo que prescritas e transmitidas entre seniores e noviços, têm sua eficácia ligada à vivência ritual. Esse tempo intersticial (simbólico e teatralizado) sem destino antecipado, ainda que almejado, aproxima-se do tempo-fluxo que, para Turner (1982: 55-59), se bem o entendo, justamente aproximaria as noções de liminar (uma fase específica dos rituais nas socie- 
dades de pequena escala) e de liminóide (os gêneros culturais e simbólicos das sociedades de grande escala). Tratar-se-ia, afinal, aqui como lá, de "símbolos na ação social, na práxis, não inteiramente postos a uma distância segura da condição humana plena [...]. A simbologia comparativa deve aprender a 'abraçar multidões' e gerar uma saudável prole intelectual com esse abraço” (Turner, I982: 55).

O simbolismo do Chihamba retornará na obra de Turner para exame detido nos dois primeiros capítulos de RD (Turner, I975a) "Chihamba, the white spirit" e "Some notes on the symbolism of Chihamba" (publicados respectivamente em I962 e I96I), e servirá de base para o experimento transcultural no terceiro capítulo, onde a brancura de Kavula será comparada a outros símbolos de brancura na literatura e religiões ocidentais, em especial, o Canto XXI do Paraíso de Dante Alighieri, a imagem de Jesus Cristo como o cordeiro de Deus, e Moby Dick, a fantástica baleia branca de Herman Melville. Nesse novo momento intelectual, como esclarece Turner (1975a: 16), Chihamba associa-se ao sentido de totalidade dos Ndembus, entendido agora não mais em sua dimensão sociológica, mas como expressão da retomada da conexão direta dos sujeitos com a unidade do fluxo da experiência, epifania, verdadeira revelação. Chihamba e Kavula condensam assim um feixe de interesses teóricos que se desdobram nos conceitos de drama social, de liminaridade e communitas, do símbolo ritual eficaz e, finalmente, da performance vista como ponto de chegada da experiência social, apreendida como um processo.

\section{NO UMBRAL DA PERFORMANCE}

Depois de Revelation and divination (1975a), Turner rumaria decididamente para o diálogo com o teatro experimental através do contato com o diretor Richard Schechner (Dawsey, 20II). Os ensaios de From ritual to theatre expressam esse encontro e falam sobre a viagem pessoal de descoberta do autor "desde os estudos antropológicos tradicionais da performance ritual para um vívido interesse no teatro moderno" (Turner, I982: 7).${ }^{28}$ E Turner logo celebraria a realização de seu desejo de uma "antropologia liberada" (Turner, I987b: 72). Seus estudos navegam agora na ampla confluência do interesse pela performance vindo tanto do campo artístico (Glusberg, 2009; Lopes, 2003) como do movimento conceitual de diversos campos de conhecimento como a linguística (Austin, 1962; Peirce, I969; Searle, 1969), a literatura oral (Zumthor, 2009), a etnomusicologia (Seeger, I994), estudos de folclore (Bauman, I977) e a própria antropologia (Malinowski, I972; Tambiah, I968; 1973). ${ }^{29}$

De fato, em muitos temas do multifacetado campo artístico da performance - como a valorização da simultaneidade de formas expressivas e de um tempo interno ao desenrolar de uma experiência; a obra tornada viva 
através do corpo presente do artista, ou mesmo a obra que é o próprio corpo do artista, e deve ser vivida junto com o público; valor da fisicalidade dessa presença mútua e das formas não verbais ou discursivas na apreensão do sentido da experiência estética; a busca de uma relação mais direta com a vida social (Glusberg, 2009) - ressoa muito daquilo que foi abarcado pelos estudos dos rituais na tradição antropológica desde Robertson Smith (2005). E tudo isso soa especialmente próximo da sensível trilha aberta por Van Gennep (I997) e reconfigurada na antropologia de Turner..$^{30}$ Vindo de um longo percurso, Turner parece responder a esse novo apelo com uma aspiração universalista, e mesmo redentora, acerca da condição humana, e também com uma profunda ânsia de interligar os diferentes temas de sua obra e de vinculá-los a uma base filosófica mais nítida. ${ }^{3 \mathrm{I}}$

A leitura dessa última fase de Victor Turner, inaugurada com From ritual to theatre (I982), é particularmente difícil pelo fato de boa parte dela ter sido editada postumamente (Turner, 1985; 1986; 1987). On the edge of the bush. Anthropology as experience (1985) foi editado por Edith Turner. O texto "Dewey, Dilthey and drama: an essay in the anthropology of experience" (I986) 32 integra a coletânea póstuma intitulada The antropology of experience, que Turner organizara com Bruner, reunindo trabalhos apresentados em um simpósio no encontro anual da Associação Americana de Antropologia, em I980. The anthropology of performance (1987a), por sua vez, foi editado por Richard Schechner, que elaboraria ele mesmo um modelo de análise de performances culturais inspirado nas ideias de Victor Turner (Schechner, I987; 20II; Schechner \& Appel, I990. Ver, também, a respeito, Silva, 2005). Os dois livros póstumos reúnem tanto textos antigos como trabalhos ensaísticos de natureza "francamente exploratória", como Turner já anunciara anteriormente (I982: 55) e, embora organizados com propósitos muito distintos, alguns de seus textos se repetem ou se recobrem. ${ }^{33}$

Nesse contexto, a metamorfose do conceito de drama social, no artigo "The anthropology of performance" (Turner, I987b), é especialmente notável. Turner vê nesse conceito um prenúncio da "virada pós-moderna", compreendida como uma reação à preocupação geral com a adequação e com a congruência que teriam presidido sua formação em antropologia. Pois com o drama social, nos diz o autor, emergiria justamente seu interesse pelo não harmônico, pelo discrepante, por regras situacionalmente incompatíveis entre si, pela natureza aberta e processual da vida social, em suma. Nesse texto, depois de discutir diferenças entre suas concepções e aquelas de Schechner e Goffman, de enfatizar a relevância dos sinais não verbais na comunicação animal e humana, Turner dá um surpreendente salto acrobático. Assumindo todos os riscos possíveis, e reagindo à crença em ordenações predeterminadas que movimentariam a tradição filosófica ocidental de Platão aos estruturalismos antropológicos (Turner, I987b: 84), Turner reafirma a 
communitas como um princípio ontológico, uma espécie de lei e fonte de toda ordenação: "O individualismo extremo apenas compreende parte do homem. O coletivismo extremo apenas compreende o homem como parte. Communitas é a lei implícita da completude (wholeness) advinda de relações entre totalidades" (Turner, I987b: 84). Mas, embora a communitas quase nunca se realize, pois que intrinsecamente dinâmica, é dela que provêm os processos e deles as possibilidades de ordenações. Turner volta, então, a seu chão: "E performances, particularmente performances dramáticas, são manifestações por excelência do processo social humano" e, por isso, a unidade de análise capaz de apreender esse processo é o drama. O drama social torna-se, agora, "a unidade empírica do processo social de onde derivaram e continuam a derivar os variados gêneros da performance cultural" (Turner, I987b: 92) ) $^{34}$ ou a "unidade espontânea da performance social humana, pois ele abole a distinção entre fluxo e reflexão [...] uma vez que, no drama social, torna-se urgente refletir acerca da causa e do motivo da ação que perturba o tecido social" (Turner, I987b: 90). Ao tomar o drama social como uma unidade espontânea, ou empírica, Turner parece abraçar um evolucionismo insustentável e naturaliza seu próprio conceito, empobrecendo-o ao retirar dele, em especial, sua moldura narrativa, ela sim, dramática.

Turner prosseguirá, ainda, desenhando, com o recurso a Dilthey, sua visão da performance como um processo no qual uma experiência se consuma e o sentido pode ser apreendido sempre de modo relativo, "malgrado todas as tentativas de cristalização do sentido do vivido" (Turner, I987b: 98). Nessa perspectiva, a forma final da escrita de um texto pode ela mesma ser vista como uma performance em que uma experiência se consuma e passado e presente se encontram. A obra de Turner não cessa de desdobrar-se, e ancestrais, afinal, nos inquietam, e mesmo por vezes nos afligem. Como no ritual Chihamba, seniores e neófitos somos sempre instados a encenar a morte de Kavula, não o ancestral exatamente, mas um ser liminar que convida a expressar e refletir. Essa incursão de leitura pela obra fecunda de Victor Turner, nosso ancestral antropológico, talvez possa ter, ela também, caráter regenerativo e aberto. 
Maria Laura Viveiros de Castro Cavalcanti é doutora em Antropologia pelo Museu Nacional/UFRJ, e professora do Departamento de Antropologia Cultural e do Programa de Pós-Graduação em Sociologia e Antropologia do Instituto de Filosofia e Ciências Sociais da Universidade Federal do Rio de Janeiro (IFCS-UFRJ). É autora de O mundo invisível: cosmologia, sistema ritual e noção da pessoa no espiritismo (I983), O rito e o tempo: ensaios sobre o carnaval (i999), Carnaval carioca: dos bastidores ao desfile (2006). Reconhecimentos: Antropologia, folclore e cultura popular (2012), seu livro mais recente, foi premiado com Menção Honrosa no concurso ANPOCS de

Obras Científicas, de 2013. 


\section{NOTAS}

I A antropologia brasileira dialogou intensamente com Victor Turner desde os anos I960 (ver as entrevistas de Roberto DaMatta e Yvonne Maggie, neste volume). Ver, entre outros, DaMatta (I979; 2000), Maggie (200I), Leopoldi (I978), Vogel, Mello \& Barros (I998), Cavalcanti (2006), Silva (2005), Dawsey (2005), Steil (1996). Três livros de Victor Turner foram traduzidos para o português: O processo ritual (1974); Floresta de símbolos: aspectos do ritual Ndembu (2005) e Drama, campos e metáforas (2008). As traduções dos livros não publicados em português citadas neste artigo foram feitas por mim.

2 A pesquisa sobre os Lunda-Ndembus, mais comumente designados como Ndembus, foi realizada no quadrante mais ao norte e mais tradicional da porção ocidental do distrito Mwinilunga, na região Noroeste da antiga Rodésia do Norte, atual Zâmbia. A pesquisa ocorreu entre dezembro de 1950 e fevereiro de I952, e entre maio de I953 e junho de I954. Para a liderança exercida por Max Gluckman no chamado grupo de Manchester e para a história do Instituto Rhodes-Livingstone, ver Engelke (2004) e Schumaker (2004; 200I).

3 A originalidade sociológica do conceito de drama social foi saudada pelo próprio Max Gluckman (I990). Geertz (I997) renovou seu enfoque quando, ao discutir o uso de metáforas conceituais no pensamento antropológico, indicou sua natureza propriamente dramatúrgica. Em Cavalcanti (2007), discuti a dimensão ficcional e poética dessa noção.

4 Como sabemos, a genealogia da noção de ritual confunde-se com a própria história da antropologia (Cavalcanti \& Gonçalves, 2009).

5 Em 1955, Turner vinculou-se à Universidade de Manchester, na Inglaterra, no Departamento liderado também por Gluckman. Durante esse período, a estadia no Centro de Estudos Avançados em Ciências Comportamentais da Universidade da Califórnia, entre I96I-I962, serviu como porta de entrada no mundo acadêmico norte-americano, onde ele assumiu, em fevereiro de I964, posto na Universidade de Cornell. Na Universidade de Chicago, para onde Turner iria em I968, ele trabalhou com uma dupla vinculação, 
ligando-se tanto ao departamento de antropologia como ao Comitê de Pensamento Social, instância multidisciplinar que lhe teria permitido mais liberdade intelectual (Engelke, 2004). Em 1977, ele foi para a Universidade de Virginia, onde, até sua morte, em I983, foi professor de antropologia da religião. Para mais detalhes da biografia de Turner, ver Babcock (1984). Ver, também, Manning (1990).

6 Edith Turner (Engelke, 2004; 2008) foi, desde o primeiro momento, uma ativa colaboradora de Turner. Depois de sua morte, em I983, ela editou a coletânea de artigos de Turner, On the edge of the bush. Anthropology as experience (1985). Voltou à África em I985, e publicou The spirit and the drum: a memoir of Africa (1987).

7 Kavula já havia sido mencionado no contexto da breve descrição desse mesmo ritual de cura na última página do primeiro artigo de Turner sobre os Ndembu, "Lunda rites and ceremonies" (1953: 56).

8 Como assinalou Peirano (I993), o sistema simbólico e sistema social tornam-se coextensivos nos trabalhos de Turner. A divisão entre social e cultural permaneceria, entretanto, firme ao longo de sua obra e está na base, por exemplo, da distinção entre as ideias de liminal e liminóide (Turner, I982: 2I-60). Essa divisão, contudo, perdeu relevância na antropologia, sobretudo a partir da obra de Claude Lévi-Strauss, com o aprofundamento da perspectiva durkheimiana e do conceito maussiano do fato social total. A sociedade é, afinal, um fato da consciência, uma representação simbólica e cultural. Ver a respeito Sahlins (I976). Para a crítica contemporânea ao próprio conceito de sociedade ver Ingold (I994).

9 Vale mencionar a coleção Symbol, myth, and ritual, organizada por Victor Turner na Universidade de Cornell. Abrangendo o que Turner chamava de antropologia simbólica e simbologia comparativa (ver Turner, I975b), o conjunto editado é notável, com pesquisas de Barbara Babcock, Mircea Eliade, Raymond Firth, Ronald Grimes, Frank Manning, Roy Wagner, entre muitos outros.

Io O par conceitual communitas/estrutura teve grande impacto na antropologia das religiões (De Boeck \& Devish, I994; Deflem, I99I; Weber, I995). No Brasil, para uma visão crítica, ver Steil (I996), entre outros. No campo das humanidades de 
modo geral, vale citar seu proveitoso uso por historiadores como Lonsdale (1993), Le Roy Ladurie (I979), entre outros.

I I A definição e discussão do drama social e de suas fases, por exemplo, será retomada inúmeras vezes. Entre elas, em Turner (2008: 33-37; I968: 89; I987a: 74-75). A cada novo interesse Turner preocupa-se em retomar, sob ângulos diversos, seus pontos de partida. Como em Turner (I982: 24): "No meu caso, fui levado na direção do estudo dos gêneros simbólicos em sociedades de larga escala por algumas implicações do trabalho de Arnold Van Gennep (que se baseava principalmente em dados de sociedades de pequena escala) em seus Ritos de passagem, publicados pela primeira vez na França, em I908".

I2 Essa definição retorna em vários momentos da obra de Turner. Ver, por exemplo, Turner (I968: I5). Assim como a oposição rígida entre ritual e cerimônia - aquele associado aos processos de transição e transformação e esta a ações confirmatórias. Comentando a obra de Turner, Grimes (I990: I4I) chamou a atenção, entre outros problemas trazidos por essa definição, para a suposição da prioridade da crença sobre o ritual e para a desconsideração das instâncias de disjunção e dissonância entre ritual e crença (Grimes, I990, p. I42-I44). A ideia do símbolo ritual como unidade última do comportamento ritual (Turner, 2005: 49), por sua vez, deixa também de fora muito do que ocorre nos rituais concretos.

I3 Vale lembrar também a metodologia de exegese dos símbolos em três níveis de significado: o exegético (o entendimento nativo), o operacional (as diversas formas de uso) e o posicional (a relação de um símbolo com outros, tanto dentro de um ritual específico como em diferentes rituais) (Turner: 2005).

I4 Ver, por exemplo, o belo exercício comparativo de análise do simbolismo das cores nos rituais Ndembu, o capítulo 3 de FS (Turner, 2005); e também, em DA (Turner, I968), a ideia de uma morfologia dos rituais de aflição, apresentada no capítulo 3.

I5 Veja-se, por exemplo, a simpatia confessa de Max Gluckman por Sandombu (I996: XIX).

I6 A dimensão conceitual da noção de rito de passagem só seria efetivamente valorizada por Turner com o já men- 
cionado artigo "Betwix, between...", de I964 (Turner, 2005). O conceito de drama social, entretanto, com sua ênfase na sequencialidade e na natureza processual da vida social, com a imbricação entre o plano individual e coletivo, parece já bastante afim daquele de rito de passagem (Van Gennep, 1977). Belmont (I979: 69) assinala como a relação do padrão sequencial dos ritos de passagem com a expressão dramática das emoções pretendidas já havia sido percebida por Van Gennep.

I7 Mukanza, ficamos sabendo com Engelke (2004: 26), é o nome fictício da aldeia Kajima, tema do primeiro artigo autoral de Edith Turner que, escrito em I954, só viria a ser publicado em I987 (Turner, E., I987).

I8 Essa relação é feita pelo próprio Turner: "Eu indiquei muitas conexões entre as ações e veículos simbólicos em Chihamba e aspectos da estrutura e da dinâmica social Ndembu. Também devotei todo um capítulo de meu livro, Cisma e continuidade, o capítulo $\mathrm{X}$, a um estudo detalhado dos principais efeitos sociais de uma performance específica do Chihamba na aldeia Mukanza e no seu campo de relacionamentos interaldeias" (Turner, 1975a: 19).

I9 O autor antevê que a aldeia Mukanza clivar-se-ia em duas - com Kasonda (sub-linhagem Malabu) e Sandombu (sub-linhagem Nyachitang'a) fundando cada qual sua própria aldeia; e com Sakazao (sub-linhagem Malabu) assumindo a chefia da aldeia Mukanza. Vale informar que nada disso, como comenta Turner no Prefácio à edição de I968 (Turner, I996, p. XXIII), veio a ocorrer. Mukanza Kabinda foi um chefe longevo e morreu em I967. Foi sucedido, sem maiores conflitos, por Kasonda. A aldeia Mukanza manteve sua integridade por mais uma geração.

$20 \mathrm{Na}$ introdução de Floresta dos símbolos (Turner, 2005), esse apanhado é brevemente retomado. Uma visão de conjunto dos rituais Ndembu é também esboçada na introdução de The drums of affliction (Turner, 1968).

2I A compreensão do potencial heurístico da noção de rito de passagem só se expressaria, como vimos, mais tarde (Turner, 2005). A atenção que esse conceito despertou na antropologia social inglesa foi assinalada pela coletânea organizada por Max Gluckman (I962), que reuniu textos de Daryll Forde, Meyer Fortes, Victor Turner e do próprio Gluckman. 
22 O material relativo a esses rituais se espalharia pela obra de Turner. Nkang'a, ritual de puberdade feminino, emerge no primeiro capítulo de FS (Turner, 2005) e é abordado também no cap. VII de DA (Turner, I968). Em FS, há também Mukanda, rito de circuncisão, e Wubinda, culto de caça, abordados respectivamente nos capítulos VII e VIII; e Ihamba, rito de aflição masculino, ligado aos rituais de caça que, enfocado no capítulo $\mathrm{X}$, retorna como foco dos capítulos centrais de DA. Isoma e Wubwaang'u, ritos de cura femininos, são o foco analítico respectivamente do primeiro e do segundo capítulos de PR (Turner, I974). Essa pulverização faz da obra de Turner também um emaranhado de referências intercruzadas.

23 Turner (I975a: 4I) nos diria mais tarde que Muchona desempenhava, junto com outros curadores, um papel importante nesse ritual. Sobre Muchona, ver em especial o capítulo VI, de FS (Turner, 2005).

24 Kavula é masculino e o espírito ancestral que aflige é sempre feminino. Toda a teatralização do Kavula é atribuição masculina (Turner, I996: 307).

25 Os textos de referência são Fortes (I945; I949), Evans-Pritchard (1948) e Fortes \& Evans-Pritchard (1940). Vale observar que também esses autores, cada qual à sua maneira, ampliariam nas fases subsequentes de suas carreiras o interesse pela dimensão simbólica da vida social. Ver, em especial, Fortes (I987) e Evans-Pritchard (I956).

26 Para uma utilização das teorias turnerianas de ritual tanto no exame da possessão pentecostal como dos projetos teatrais de Grotowski, ver Alexander (I99I). Para a influência de Turner no campo das performances culturais, ver St. John (2008).

27 Ou ainda: "o ritual compensa as deficiências da estrutura política ou de parentesco em uma sociedade lábil” (Turner, I996: 303).

28 Resumindo um argumento complexo, na leitura de DaMatta (2000), para Victor Turner a experiência da liminaridade estaria associada à coletivização e seria positivada por essa razão, sem que o autor se desse conta de que estaria buscando nisso um contraponto à própria ideologia individualista de seu sistema cultural. Para DaMatta, a experiência da liminaridade pode assumir conotações distintas e, em 
um sistema holístico e relacional como o brasileiro, ela pode elaborar justamente a individualização, promovendo um "eu" e não um "nós" essencial. Isso parece especialmente verdadeiro no ambiente dos processos rituais e festivos da cultura popular contemporânea, onde o talento de muitos artistas populares emerge individualizando-os em ambientes profundamente relacionais e mesmo clientelísticos. Ver, por exemplo, o caso de Seu Betinho, Herberth Mafra Reis, o Pai Francisco de um Bumba-meu-boi de Zabumba, em São Luís do Maranhão, foco do trabalho de Carvalho (20II).

29 Para um apanhado de diferentes teorias do drama e da performance no campo antropológico e artístico, ver Silva (2005). Para a vertente performativa na antropologia, ver Peirano (2002). Ver, também, Travassos (2006).

30 Vale notar que no âmbito das performances artísticas se faz presente também uma certa nostalgia primitivista que apela diretamente aos estudos antropológicos: "Ao atualizar a função mediadora do corpo, as performances [artísticas] remetem a numerosas cerimônias primitivas e, em particular, à magia" (Glusberg, 2009: 103).

3I Wilhem Dilthey (20I0) e John Dewey (2010) ocupam lugar de relevo nessa busca. Dawsey (2005) propôs sugestiva leitura da presença desses dois filósofos nesse momento da obra de Turner como figuras regeneradoras.

32 Este texto está traduzido na Cadernos de Campo, I4/I3, 2005, p. I77-I85.

33 Embora o escopo de On the edge of the bush [EB] (Turner, I985) seja bem mais amplo do que The anthropology of performance [AP] (Turner, I987a), esses dois livros póstumos reproduzem por vezes os mesmos textos. É o caso de "The anthropology of performance" ( $8^{\circ}$ capítulo de EB e o terceiro artigo de AP); ou de "Body, brain, and culture" (o II ${ }^{\circ}$ capítulo de EB e o último artigo de AP). Em cada um dos livros, encontram-se versões diferentes do diálogo de Victor Turner com a pesquisa de Yvonne Maggie (200I); e em AP está o artigo "Carnival in Rio" que registra o diálogo de Turner com Roberto DaMatta (I979). Por sua vez, muito do texto de Turner "Dewey, Dilthey, and drama", publicado em I986, está contido no capítulo 9, intitulado "Experience and performance: towards a new processual anthropology", de EB. 
34 Turner (I987b: 93-94) ressalta que uma fase em especial do drama social - a fase regenerativa (aquela onde se realizam rituais) - seria a fonte geradora das performances e narrativas culturais (do ritual ao filme e ao teatro; do mito ao romance), nela passado e presente se encontrariam.

\section{REFERÊNCIAS BIBLIOGRÁFICAS}

Alexander, Bobby C. (I99I). Victor Turner revisited: ritual as social change. Atlanta: Scholars Press.

Austin, John. (1962). How to do things with words. Cambridge: Harvard University Press.

Babcock, Barbara A. (I984). Obituary: Victor W. Turner (1920-1983). The Journal of American Folklore, 97/386, out./dez., p. 46I-464.

Belmont, Nicole. (1979). Arnold Van Gennep. The creator of French ethnography. Chicago/Londres: The University of Chicago Press.

Bauman, Richard. (1977). Verbal art as performance. Prospect Heights, Illinois: Waveland Press.

Carvalho, Luciana Gonçalves de. (20I I). A graça de contar. Um Pai Francisco no bumba meu boi do Maranhão. Rio de Janeiro: Aeroplano.

Cavalcanti, Maria Laura Viveiros de Castro. (2012). Luzes e sombras no dia social. O símbolo ritual em Victor Turner. Horizontes Antropológicos, I8/37, jan./jun., p. I03-I3I.

Cavalcanti, Maria Laura Viveiros de Castro. (2007). Drama social, notas sobre um tema de Victor Turner. Cadernos de Campo, 16/16, dez., p. I27-138.

Cavalcanti, Maria Laura Viveiros de Castro. (2006). Carnaval carioca: dos bastidores ao desfile. Rio de Janeiro: Ed. UFRJ.

Cavalcanti, Maria Laura Viveiros de Castro \& Gonçalves, José Reginaldo S. (orgs.). (2009). Apresentação. In: As festas e os dias. Ritos e sociabilidades festivas. Rio de Janeiro: Contracapa, p. 7-ro.

DaMatta, Roberto. (2007). Conversa com Roberto DaMatta. Entrevista por Carmen Rial e Lia Zanota Machado. In: $25^{2}$ Reunião Brasileira de Antropologia. Conferências e diálogos: saberes e práticas antropológicas. Blumenau: Nova Letra, p. 259-28I. 
DaMatta, Roberto. (2000). Individualidade e liminaridade: considerações sobre os ritos de passagem e a modernidade. Mana, 6/I, p. 7-29.

DaMatta, Roberto (org.). (1983). Edmund Leach. Rio de Janeiro: Ática, I983. (Coleção Grandes Cientistas Sociais)

DaMatta, Roberto. (1979). Carnavais, malandros e heróis. Por uma sociologia do dilema brasileiro. Rio de Janeiro: Zahar.

Dawsey, John Cowart. (20II). Schechner, teatro e antropologia. Cadernos de Campo, 20/20, p. 207-2II.

Dawsey, John Cowart. (2005). Victor Turner e a antropologia da experiência. Cadernos de Campo, I3/14, p. I63-I76.

De Boeck, Filip \& Devish, René. (I994). Ndembu, Lunda and Yaka divination compared: from representation and social engineering to embodiment and worldmaking. Journal des Réligions Africaines, XXIV/2, p. I-23.

Deflem, Mathieu. (I99I). Ritual, anti-structure, and religion: a discussion of Victor Turner's processual symbolic analysis. Journal for the Scientific Study of Religion, 30/I, p. I-25.

Dewey, John. (2010). Arte como experiência. São Paulo: Martins Fontes.

Dilthey, Wilhem. (20I0). Filosofia e educação. São Paulo: Edusp. Douglas, Mary. (1976). Pureza e perigo. São Paulo: Perspectiva. Durkheim, Émile. (1996). As formas elementares da vida religiosa. São Paulo: Martins Fontes.

Engelke, Mathew. (2008). An interview with Edith Turner. In: St. John, Graham (org.). Victor Turner and contemporary cultural performance. Nova York: Berghahn Books, p. 275-276. Engelke, Mathew. (2004). The endless conversation: Fieldwork, writing, and the marriage of Victor and Edith Turner. In: Handler, Richard (org.). Significant others: interpersonal and professional commitments in anthropology. Winsconsin: The University of Wisconsin Press, p. 6-49.

Evans-Pritchard, Edward E. (2005). Bruxaria, oráculos e magia entre os Azande. Rio de Janeiro: Zahar.

Evans-Pritchard, Edward E. (I956). Nuer religion. Oxford: Oxford University Press.

Evans-Pritchard, Edward E. (1948). The divine kingship of the Shilluk of the Nilotic Sudan. Cambridge: Cambridge University Press. 
Fortes, Meyer. (1987). Religion, morality and the person: essays on Tallensi religion. Cambridge: Cambridge University Press.

Fortes, Meyer. (1949). The web of kinship among the Tallensi. Londres: Oxford University Press.

Fortes, Meyer. (1945). The dynamics of clanship among the Tallensi. Londres: Oxford University Press.

Fortes, Meyer \& Evans-Pritchard, Edward E. (orgs.). (I940). African political systems. Londres: Oxford University Press. Geertz, Clifford. (1997). O saber local. Petrópolis: Vozes. Gluckman, Max. (1996). Preface. In: Turner, Victor. Schism and continuity in an African society. Manchester: Manchester University Press, p. XV-XX.

Gluckman, Max. (1990). O material etnográfico na antropologia social inglesa. In: Zaluar, Alba (org.). Desvendando máscaras sociais. Rio de Janeiro: Livraria Francisco Alves, p. 64-76.

Gluckman, Max. (1974). Ritos de rebelião. Cadernos de Antropologia, n. 4. Brasília: Ed. UnB.

Gluckman, Max. (1963). Order and rebellion in tribal Africa. Londres: Cohen \& West.

Gluckman, Max (org.) (I962). Essays on the ritual of social relations. Manchester: Manchester University Press.

Grimes, Ronald L. (I990). Victor Turner's definition, theory and sense of ritual. In: Ashley, Kathleen (org.). Victor Turner and the construction of cultural criticism: between literature and anthropology. Indiana: Indiana University Press, p. I4I-I46.

Glusberg, Jorge. (2009). A arte da performance. São Paulo: Perspectiva.

Ingold, Tim (org.). (I994). Introduction to social life. In: Companion encyclopedia of anthropology. Londres/Nova York: Routledge, p. 735-755.

Langer, Susanne. (2003 [1953]). Sentimento e forma. São Paulo: Perspectiva.

Lenclud, Gérard. (I99I). Turner, Victor Witte. In: Bonte, Pierre \& Izard, Michel (orgs.). Dictionnaire de l'ethnologie et de l'anthropologie. Paris: Presses Universitaires de France, p. 72I-722.

Leopoldi, José Sávio. (1978). Escola de samba, ritual e sociedade. Petrópolis: Vozes. 
Le Roy Ladurie, Emmanuel. (I979). Le carnaval des romans. Paris: Gallimard.

Lévi-Strauss, Claude. (20I I). O homem nu. Mitológicas 4. São Paulo: Cosac Naify.

Lévi-Strauss, Claude. (I976). O pensamento selvagem. São Paulo: Cia. Editora Nacional.

Lonsdale, Steven H. (1993). Dance and ritual play in Greek religion. Baltimore: The Johns Hopkins University Press.

Lopes, Antonio Herculano. (2003). Performance e história (ou como a onça, de um salto, foi ao Rio do princípio do século e ainda voltou para contar a história). Percevejo, II/I 2, p. 5-I6.

Maggie, Yvonne. (200I). Guerra de orixá: um estudo de ritual e conflito. Rio de Janeiro: Zahar.

Malinowski, Bronislaw. (I972). O problema do significado em linguagens primitivas. In: Ogden, Charles K. \& Richards, Ivor A. (orgs.) O significado do significado. Rio de Janeiro: Zahar.

Manning, Frank E. (I990). Victor Turner's career and publication. In: Ashley, Kathleen (org.). Victor Turner and the construction of cultural criticism: between literature and anthropology. Indiana: Indiana University Press, p. I70-I77.

Peirano, Mariza (org.). (2002). A análise antropológica dos rituais. In: $\mathrm{O}$ dito e o feito. Ensaios de antropologia dos rituais. Rio de Janeiro: Relume Dumará, p. I7-40.

Peirano, Mariza. (1993). As árvores Ndembu, uma re-análise. Anuário Antropológico, I99o. Rio de Janeiro: Tempo Brasileiro, p. 9-64.

Peirce, Charles. (I990). Semiótica. São Paulo: Perspectiva.

Richards, Audrey. (1982 [1956]). Chisungu: a girl's initiation ceremony among the Bemba of Zambia. Londres: Routledge.

Sahlins, Marshall. (1976). Culture and practical reason. Chicago: The University of Chicago Press.

Searle, John. (1969). Speech acts. An essay in the philosophy of language. Cambridge: Cambridge University Press.

Seeger, Anthony. (1994). Music and dance. In: Ingold, Tim (org.). Companion enciclopedia of anthropology. Londres/Nova York: Routledge. 
Schechner, Richard. (200I). Pontos de contato entre o pensamento antropológico e teatral. Cadernos de Campo, 20, jan./dez., p. 213-236.

Schechner, Richard. (1987). Preface: Victor Turner's last adventure. In: Turner, Victor. The anthropology of performance. Nova York: PAJ Publications, p. 7-20.

Schechner, Richard \& Appel, Willa (orgs.). (I990). By means of performance. Intellectual studies of theatre and ritual. Cambridge: Cambridge University Press.

Schumaker, Lyn. (2004). The director as significant other. Max Gluckman and Team Fieldwork at the Rhodes-Livingstone Institute. In: Handler, Richard (org.). Significant others: interpersonal and professional commitments in anthropology. Winsconsin: The University of Wisconsin Press, p. 9I-I30. Schumaker, Lyn. (200I). Africanizing anthropology. Durham/ Londres: Duke University Press.

Silva, Rubens Alves. (2005). Entre "artes" e "ciências": as noções de performance e drama no campo das ciências sociais. Horizontes Antropológicos, I I/24, p. 35-65.

Smith, Robertson. (2005 [1894]). Lectures on the religion of the Semites. Londres: Adamant Media Corporation. (Elibron Classic Series)

St. John, Graham (org.). (2008). Introduction. In: Victor Turner and contemporary cultural performance. Nova York: Berghahn Books, p. I-37.

Steil, Carlos. (I996). O sertão das romarias: um estudo antropológico do santuário de Bom Jesus da Lapa - Bahia. Petrópolis: Vozes.

Tambiah, Stanley. (1973). Form and meaning of magical acts. In: Horton, Robin \& Finnegan, Ruth (orgs.). Modes of thought. Londres: Faber and Faber, p. I99-229.

Tambiah, Stanley. (I968). The magical power of words. Man, 3/2, p. I75-208.

Travassos, Elizabeth. (2006). A noção de performance e a mistura de gêneros. Comunicação apresentada na $25^{\mathrm{a}}$ Reunião Brasileira de Antropologia, Goiânia, GT Ritos da Cultura Popular.

Turner, Edith. (1987). The spirit and the drum: a memoir of Africa. Tucson: Arizona University Press. 
Turner, Victor. (2008). Drama, campos e metáforas. Niterói: EdUFF.

Turner, Victor. (2005 [1967]). Floresta dos símbolos: aspectos do ritual Ndembu. Niterói: EdUFF.

Turner, Victor. (1996 [1957]). Schism and continuity in an African society. Manchester: Manchester University Press.

Turner, Victor. (I987a). The anthropology of performance. Nova York: PAJ Publications.

Turner, Victor. (1987b). The anthropology of performance. In: The Anthropology of performance. Nova York: PAJ Publications, p. 72-98.

Turner, Victor. (1986). Dewey, Dilthey and drama: an essay in the anthropology of experience. In: Turner, Victor \& Bruner, Edward M. (orgs.). The anthropology of experience. Urbana: University of Illinois Press, p. 33-44.

Turner, Victor. (1985). On the edge of the bush: Anthropology as experience. Tucson: Arizona University Press.

Turner, Victor. (1982). From ritual to theatre: the human seriousness of play. Nova York: PAJ Publications.

Turner, Victor. (1975a). Revelation and divination in Ndembu ritual. Ithaca: Cornell University Press.

Turner, Victor (1975b). Symbolic studies. Annual Review of Anthropology, 4, p. I45-I6I.

Turner, Victor. (1974 [1969]). O processo ritual: estrutura e anti-estrutura. Petrópolis: Vozes.

Turner, Victor. (I968). The drums of affliction: a study of religious processes among the Ndembu of Zambia. Oxford: Oxford University Press.

Turner, Victor. (1953). Lunda rites and ceremonies. The Occasional Papers of the Rhodes-Livingstone Museum, Io, p. 335-388. University of Zambia by Manchester University Press.

Turner, Victor \& Bruner, Edward M. (1986). The anthropology of experience. Urbana/Chicago: University of Illinois Press.

Turner, Victor \& Turner, Edith. (1978). Image and pilgrimage in Christian culture. Nova York: Columbia University Press.

Van Gennep, Arnold. (1977 [I909]). Os ritos de passagem. Petrópolis: Vozes. 
Vogel, Arno; Mello, Marco Antonio da S. \& Barros, José Flávio P. (1998). Galinha d'Angola: iniciação e identidade na cultura afro-brasileira. Rio de Janeiro: Pallas.

Weber, Donald. (1995). From limen to border: a meditation on the legacy of Victor Turner. American Cultural Studies, 47/3, p. 525-536.

Wilson, Monica. (1957). Rituals of kinship among the Nyakyusa. Oxford: Oxford University Press.

Wilson, Monica. (I954). Nyakyusa ritual and symbolism. American Anthropologist: New Series, 56/2, Parte I, p. 228-24I. Zumthor, Paul. (2009) Falando de Idade Média. São Paulo: Perspectiva. 


\section{DRAMA, RITUAL E PERFORMANCE} EM VICTOR TURNER

Resumo

Este estudo da obra de Victor Turner toma como ponto de partida seu profundo interesse pelos símbolos e por sua ação na experiência social. Ritual é o tema que abarca esse interesse, desdobrando-se de diversos modos nas sucessivas fases de sua trajetória intelectual. Nesta incursão, Chihamba, um ritual de cura Ndembu, e o personagem mítico Kavula - que emergem já em seu primeiro livro Schism and continuity in an African society (I996 [1957]) - são tomados como fio condutor para a apreensão dos conceitos de drama social, de símbolo ritual e de performance, três fulcros das contribuições centrais de Victor Turner à teoria antropológica.

\section{DRAMA, RITUAL AND PERFORMANCE IN VICTOR TURNER'S WORK}

Palavras-chave Drama; Ritual; Performance; Victor Turner; Antropologia.
Keywords
Drama; Ritual;
Performance;
Victor Turner;
Anthropology.

This study of Victor Turner's work takes as a starting point his deep interest in symbols and its effect on social experience. Ritual is the theme that embraces Turner's interest, unfolding in many ways throughout the successive phases of his intellectual career. Chihamba, a healing Ndembu ritual, and the mythical character Kavula - that already appear in his first book Schism and continuity in an African society (1996 [1957]) - are used as guidelines for the apprehension of the concepts of social drama, ritual symbol, and performance, three clusters of Victor Turner's main contributions to anthropological theory. 